\title{
A STUDY ON MATERNAL SERUM TOTAL THIOLS AND HIGHLY SENSITIVE C-REACTIVE PROTEIN AS INDICATORS OF OXIDATIVE STRESS AND INFLAMMATION IN PREECLAMPSIA AND THEIR CORRELATION WITH OPHTHALMIC MANIFESTATIONS
}

\author{
Rakhi Bandyopadhyay¹, Tanima Mandal², Pinaki Sarkar³, Jhuma Biswas 4
}

${ }^{1}$ Associate Professor, Department of Ophthalmology, BSMCH, Bankura, West Bengal, India.

${ }^{2}$ Assistant Professor, Department of Biochemistry, BIN, IPGMER, Kolkata, West Bengal, India.

3 Professor and HOD, Department of Biochemistry, BSMCH, Bankura, West Bengal, India.

${ }^{4}$ Associate Professor, Department of Obstetrics and Gynaecology, CNMC\&H, Kolkata, West Bengal, India.

\section{ABSTRACT}

\section{BACKGROUND}

Preeclampsia is a serious pregnancy specific complication, the etiopathogenesis of which is still obscure in many aspects, despite improvements in diagnosis and treatment. Preeclampsia can be associated with ophthalmic manifestations, as part of end organ damage and the role of oxidative stress and inflammation in the pathogenesis of eye changes was evaluated in this study. We wanted to determine the serum levels of total thiol as a measure of oxidative stress and highly sensitive C-reactive protein (hsCRP) as a measure of systemic inflammation and compare these parameters with that of normal pregnancy, to assess the relevance of these parameters in causing eye changes in preeclampsia.

\section{METHODS}

A cross-sectional study was done with 33 patients of preeclampsia (21 patients of non-severe preeclampsia and 12 patients of severe preeclampsia) and 25 individuals of normal pregnancy who served as controls. Serum total thiols and hs-CRP were measured in these three groups and the values compared. Correlation between total thiol and hs-CRP with age, systolic blood pressure, diastolic blood pressure and retinopathy was done using Pearson's correlation coefficient. Analysis of variance was done to find out the effect of severity of preeclampsia on systolic and diastolic blood pressure, retinopathy, total thiols and hs-CRP among the pregnant participants.

\section{RESULTS}

Serum total thiol levels were lower and serum hs-CRP was higher than the control group, with $\mathrm{p}<0.01$. Correlation analysis showed a very significant positive association of retinopathy with systolic BP, diastolic BP and serum hs-CRP level ( $p<0.01)$ and a negative correlation with serum total thiol levels $(\mathrm{p}<0.01)$. Systolic BP correlated positively with diastolic BP $(\mathrm{p}<0.01)$ and hs-CRP correlated negatively with serum total thiol $(\mathrm{p}<0.01)$. Computed $\mathrm{F}$ values of all variables reveals that there is a significant difference among mothers with normal pregnancies $(n=25)$, non- severe preeclampsia $(n=21)$ and severe preeclampsia $(n=12)$ with respect to systolic blood pressure, diastolic blood pressure, retinopathy, hs-CRP and total thiols at $p<0.01$ level of significance.

\section{CONCLUSIONS}

An increased level of serum total thiol and hs-CRP was found in preeclampsia and severe preeclampsia as compared to normal pregnancy, that correlated with retinopathy. Total thiols and hs-CRP can be useful in the prediction and diagnosis of preeclamptic retinopathy.

\section{KEY WORDS}

Preeclampsia, Total Thiols, hs- CRP, Oxidative Stress, Retinopathy

HOW TO CITE THIS ARTICLE: Bandyopadhyay R, Mandal T, Sarkar P, et al. A study on maternal serum total thiols and highly sensitive c-reactive protein as indicators of oxidative stress and inflammation in preeclampsia and their correlation with ophthalmic manifestations. J. Evolution Med. Dent. Sci. 2019;8(23):1825-1829, DOI: 10.14260/jemds/2019/401

\section{BACKGROUND}

Preeclampsia is a serious complication of pregnancy resulting in maternal and foetal morbidity and mortality. The worldwide incidence of preeclampsia is around 2 to $10 \%$.[1]

'Financial or Other Competing Interest': None.

Submission 28-04-2019, Peer Review 30-05-2019,

Acceptance 01-06-2019, Published 10-06-2019.

Corresponding Author:

Tanima Mandal,

C/o. Sudip Kumar Saha,

Sarat Apartment, Block-B,

Flat No. 302, 160, B. K. Street,

Uttarpara, Hooghly-712258,

West Bengal, India.

E-mail: tanima.saha01@gmail.com

DOI: $10.14260 /$ jemds $/ 2019 / 401$

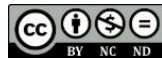

In spite of advancements in modern obstetrics, the etiopathogenesis of preeclampsia is still incompletely understood.[2] There is possibly shallow invasion of trophoblasts in the early stages of placentation and incomplete remodelling of the maternal spiral arteries, with increased arterial resistance. This leads to intermittent and pulsatile flow of blood, with uteroplacental arterial insufficiency. This contributes to chronic placental ischaemia and reperfusion type of tissue injury, with release of inflammatory mediators in the bloodstream. C- reactive protein is an acute phase reactant and a sensitive marker of inflammation in the body. Pregnancy itself, is associated with some degree of systemic inflammation [3] and excessive inflammation may play a role in pregnancies complicated by preeclampsia. 
Chronic placental ischaemia leads to production and release of free radicals into the maternal bloodstream. The resultant vasospasm, endothelial dysfunction and increased vascular peripheral resistance eventually lead to end organ damage. The eye is one such organ, which being highly vascularised, is especially susceptible to alterations of hypoxia and reoxygenation. Visual problems, due to end organ damage, have been found to occur in patients with severe preeclampsia.

Free radicals when produced in excess lead to oxidative stress and overwhelms the antioxidant capacity of the body. Thiols constitute a major portion of the antioxidant pool present in the human body. Total thiols constitute both intracellular and extracellular thiol in free form and bound to proteins. Serum total thiol estimation therefore provides measurement of the in vivo redox state, as thiols combat with free radicals to form disulphide. Decreased total thiol levels have been documented in various diseases like diabetes mellitus, neurological diseases, cardiovascular diseases and kidney diseases.

Extensive literature search did not yield studies evaluating association of serum total thiols and hs-CRP with preeclampsia induced eye changes. This study therefore will help to understand the correlation of inflammation and oxidative stress with ophthalmic manifestations. The future may even hold promise in the formulation of new treatment modalities in this condition.

\section{METHODS}

The study was designed as a single institutional crosssectional that was conducted by the department of Biochemistry, Ophthalmology, Gynaecology and Obstetrics of Bankura Sammilani Medical College and Hospital, a tertiary care government hospital in West Bengal, for a period of six months.

The study protocol and the informed consent forms were both approved by the Institutional Ethical Committee.

25 consecutive patients of non- severe preeclampsia and 12 patients of severe preeclampsia, in the third trimester, with singleton pregnancy, admitted for delivery in the Department of Gynaecology and Obstetrics, formed the cohort for this study. 25 patients in the third trimester who were admitted with uncomplicated pregnancies served as control group.

\section{Inclusion Criteria}

Patients of preeclampsia was based on the guidelines of the American College of Obstetricians and Gynecologists Task force on Hypertension in pregnancy (2013).

- Non- severe preeclampsia defined as systolic blood pressure $\geq 140 \mathrm{~mm} \mathrm{Hg}$ or diastolic blood pressure $\geq 90$ mmHg on two separate measurements, at least 4 hours apart, in a previously normotensive patient, after 20 weeks of gestation

- $\quad$ Severe preeclampsia defined as systolic blood pressure $\geq$ $160 \mathrm{mmHg}$ or diastolic blood pressure $\geq 110 \mathrm{~mm} \mathrm{Hg}$.

\section{Exclusion Criteria}

- Twin pregnancy.

- Gestational age less than 20 weeks.

- Pre-existing hypertension and diabetes.

- Pre-existing eye diseases.
- Any active infection.

- Any chronic inflammation.

- Use of nonsteroidal anti-inflammatory drugs or steroids.

- Patients in labour.

- Patients with eclampsia.

\section{Study Technique}

a. Ophthalmological Examination

All patients underwent a dilated examination of the retina after full pupillary dilatation with Tropicamide and Phenylephrine eye drops instilled thrice at ten-minute intervals, at the bedside, with a direct ophthalmoscope.

Retinopathy was graded according to the Keith-Wegener classification as follows:

Grade 1: Generalised constriction of vessels.

Grade 2: Generalised and focal constriction of vessels.

Grade 3: Haemorrhage and exudates.

Grade 4: All of the above with oedema of the optic nerve head.

Choroidopathy in hypertensive retinopathies characterised by choroidal infarcts and exudative retinal detachment. Severe complications noted include cortical blindness, central retinal artery or vein occlusion, ischaemic optic neuropathy, optic neuritis and Purtscher's like retinopathy.

\section{b. Biochemical Tests}

All patients had estimation of serum total thiol by the method of Hu et al using DTNB and TRIS-EDTA buffer. ${ }^{[4]}$ Serum was mixed with TRIS-EDTA buffer, DTNB and absolute methanol. Incubation was done at room temperature for 30 minutes. After centrifugation, absorbance was taken at $412 \mathrm{~nm}$ by the UV -VIS Double Beam Spectrophotometer using suitable reference material. Concentration of total thiol was calculated as absorbance $/ \mathrm{e} \times 20[\mathrm{e}=0.0136$ micromoles/litre, taking dilution factor of 20]

Highly sensitive C- reactive protein (hs-CRP) was quantitatively estimated by the immunoturbidimetric method (ITA) and absorbance was read at $570 \mathrm{~nm}$. The hs-CRP concentration was determined from a calibration curve developed from hs-CRP standards of known concentration. The test was done, as per instructions, given in the reagent kit of Erba Mannheim.

Serum hs-CRP Levels, as classified by the American Heart Association Centre for Disease Control from PopulationBased Studies, was used in this Study-

- $\quad$ Serum hs-CRP $\leq 1 \mathrm{mg} / \mathrm{l}$ is estimated to have low risk.

- Serum hs-CRP between 1-3 mg/l is estimated to have intermediate risk.

- $\quad$ Serum hs-CRP $\geq 3 \mathrm{mg} / \mathrm{l}$ is estimated to have high risk.

\section{Statistical Analysis}

SPSS 20.0 Statistical software (SPSS Inc. Chicago, IL) was used to analyse the data obtained in this study. Continuous data were presented as mean and standard deviation (SD). After using the Shapiro- Wilk test, data were found to have normal distribution. One-way ANOVA was done to compare the differences in the parameters between the three groups. Pearson's correlation coefficient was measured to find correlation among the different variables in the patients. 


\section{RESULTS}

\begin{tabular}{|c|c|c|c|c|c|}
\hline Parameter & Group & Mean & $\begin{array}{l}\text { Standard } \\
\text { Deviation } \\
\end{array}$ & F Value & \begin{tabular}{|c|}
$p$ \\
Value
\end{tabular} \\
\hline \multirow{3}{*}{ Age } & $\begin{array}{c}\text { Normal } \\
\text { pregnancy }(n=25)\end{array}$ & 23.00 & 2.32 & \multirow{3}{*}{1.7329} & \multirow{3}{*}{.1863} \\
\hline & $\begin{array}{c}\text { Non-severe } \\
\text { Preeclampsia( }(n=21)\end{array}$ & 24.43 & 2.60 & & \\
\hline & $\begin{array}{c}\text { Severe Preeclampsia } \\
(\mathrm{n}=12)\end{array}$ & 24.00 & 3.36 & & \\
\hline \multirow{3}{*}{$\begin{array}{l}\text { Systolic } \\
\text { BP }\end{array}$} & Normal pregnancy & 122.80 & 4.08 & \multirow{3}{*}{$528.68^{* *}$} & \multirow{3}{*}{$\mathrm{P}<.01$} \\
\hline & $\begin{array}{c}\text { Non-severe } \\
\text { Preeclampsia }\end{array}$ & 153.62 & 9.97 & & \\
\hline & Severe Preeclampsia & 206.57 & 7.27 & & \\
\hline \multirow{3}{*}{$\begin{array}{l}\text { Diastolic } \\
\text { BP }\end{array}$} & Normal pregnancy & 81.68 & 5.02 & \multirow{3}{*}{$108.77^{* *}$} & \multirow{3}{*}{$\mathrm{P}<.01$} \\
\hline & $\begin{array}{c}\text { Non -severe } \\
\text { Preeclampsia }\end{array}$ & 96.38 & 6.24 & & \\
\hline & \begin{tabular}{|l|} 
Severe Preeclampsia \\
\end{tabular} & 111.71 & 7.06 & & \\
\hline \multirow{3}{*}{ Retinopathy } & Normal pregnancy & 0.00 & 0.00 & \multirow{3}{*}{$203.67^{* *}$} & \multirow{3}{*}{$\mathrm{P}<.01$} \\
\hline & $\begin{array}{c}\text { Non -severe } \\
\text { Preeclampsia }\end{array}$ & 1.38 & 0.74 & & \\
\hline & \begin{tabular}{|l} 
Severe Preeclampsia \\
\end{tabular} & 3.57 & 0.53 & & \\
\hline \multirow{3}{*}{$\begin{array}{l}\text { Total } \\
\text { Thiols }\end{array}$} & Normal pregnancy & 2.63 & 0.38 & \multirow{3}{*}{$888.04^{* *}$} & \multirow{3}{*}{$\mathrm{P}<.01$} \\
\hline & $\begin{array}{c}\text { Non-severe } \\
\text { Preeclampsia } \\
\end{array}$ & 8.89 & 1.15 & & \\
\hline & \begin{tabular}{|l|} 
Severe Preeclampsia \\
\end{tabular} & 13.04 & 0.26 & & \\
\hline \multirow{3}{*}{\begin{tabular}{|c|} 
Highly \\
Sensitive \\
C-Reactive \\
Protein \\
\end{tabular}} & Normal pregnancy & 546.00 & 13.69 & \multirow{3}{*}{$278.27^{* *}$} & \multirow{3}{*}{$\mathrm{P}<.01$} \\
\hline & $\begin{array}{c}\text { Non- severe } \\
\text { Preeclampsia }\end{array}$ & 427.41 & 11.005 & & \\
\hline & Severe Preeclampsia & 311.41 & 59.98 & & \\
\hline
\end{tabular}

Table 1. Mean, Standard Deviation, F ratio ( $p$ value), Effect Size of Comparison among Mothers with Normal Pregnancy ( $n=25)$, NonSevere Preeclampsia $(n=21)$ and Severe Preeclampsia $(n=12)$ with Respect to Different Clinical Parameters

$*=0.05$ level of significance; ${ }^{* *}=0.01$ level of significance

\begin{tabular}{|c|c|c|c|c|c|c|}
\hline & Age & $\begin{array}{c}\text { Systolic } \\
\text { BP }\end{array}$ & $\begin{array}{c}\text { Diastolic } \\
\text { BP }\end{array}$ & Retinopathy & $\begin{array}{c}\text { HS- } \\
\text { CRP }\end{array}$ & $\begin{array}{c}\text { Total } \\
\text { Thiol }\end{array}$ \\
\hline Age & 1 & -0.152 & -0.11 & -0.163 & $0.112^{*}$ & -0.103 \\
\hline Systolic BP & & 1 & $0.723^{* *}$ & $0.837^{* *}$ & $0.918^{* *}$ & $-0.786^{* *}$ \\
\hline Diastolic BP & & & 1 & $0.731^{* *}$ & $0.766^{* *}$ & $-0.538^{* *}$ \\
\hline Retinopathy & & & & 1 & $0.768^{* *}$ & $-0.757^{* *}$ \\
\hline hs-CRP & & & & & 1 & $-0.747^{* *}$ \\
\hline Total Thiol & & & & & & $\mathbf{1}$ \\
\hline
\end{tabular}

Table 2. Pearson's Correlation Coefficients(r) of Different Parameters in Preeclampsia (n=33)

\begin{tabular}{|c|c|c|c|c|c|c|}
\hline & Age & $\begin{array}{c}\text { Systolic } \\
\text { BP }\end{array}$ & $\begin{array}{c}\text { Diastolic } \\
\text { BP }\end{array}$ & Retinopathy & $\begin{array}{c}\text { HS- } \\
\text { CRP }\end{array}$ & $\begin{array}{c}\text { Total } \\
\text { Thiol }\end{array}$ \\
\hline Age & 1 & -0.197 & -0.193 & NA & 0.454 & 0.111 \\
\hline Systolic BP & & 1 & $0.501^{*}$ & NA & 0.160 & -0.04 \\
\hline Diastolic BP & & & 1 & NA & 0.168 & -0.252 \\
\hline Retinopathy & & & & 1 & NA & NA \\
\hline hs-CRP & & & & & 1 & 0.527 \\
\hline Total Thiol & & & & & & $\mathbf{1}$ \\
\hline
\end{tabular}

Table 3. Pearson's Correlation Coefficients (r) of Different

Parameters in Normal Pregnancy (Control Group) $(n=25)$

Computed $\mathrm{F}$ values, as depicted in Table 1, of all variables like systolic BP, diastolic BP, retinopathy, total thiols and hsCRP (528.68, 108.77, 203.67, 888.04, 278.27 respectively ) are statistically significant at $\mathrm{p}<0.01$ level with respect to severity of preeclampsia. In other words, there is a significant difference among mothers with normal pregnancies, nonsevere preeclampsia and severe preeclampsia with respect to systolic blood pressure, diastolic blood pressure, retinopathy, hs-CRP and total thiols at 0.01 level of significance $(p<0.01)$. Mean scores of all parameters, hence it can be interpreted that null hypothesis is rejected at 0.01 level of significance. In other words, there is a significant difference among mothers with normal pregnancies $(n=25)$, preeclampsia $(n=21)$ and severe preeclampsia $(n=12$.) with respect to systolic $B P$, diastolic BP, retinopathy, hs-CRP and total thiols at 0.01 level of significance $<0.01$. Mean scores of all parameters of mothers with severe preeclampsia reveals that this condition is more detrimental as compared to preeclampsia and as compared to women with normal pregnancy.

Table 2 shows the correlation of different parameters in patients of preeclampsia and severe preeclampsia using Pearson's correlation coefficients ( $r$ ) reveals a positive statistically very significant association between retinopathy with systolic BP, diastolic BP and serum hs-CRP level $(p<0.01)$. A statistically very significant negative correlation was found between retinopathy with serum total thiol levels $(\mathrm{p}<0.01)$. Systolic BP showed a very strong positive correlation with diastolic $B P$ with $p<0.01$. The serum level of hs-CRP was found to correlate negatively very strongly with serum total thiols $(\mathrm{p}<0.01)$

As expected, no significant association was found among the different parameters of Total thiol, hs-CRP, systolic BP and diastolic BP with retinopathy, as no retinopathy was found among the participants of normal pregnancy.

\section{DISCUSSION}

Many aspects of the etiopathogenesis of preeclampsia remains obscure and open to research, despite diagnostic and therapeutic advancements. Placental hypoxia in this condition leads to endothelial dysfunction with end organ damage including retinopathy.[5,6] Normal pregnancy, per se is a proinflammatory state but in preeclampsia, excessive inflammation and production of reactive oxygen species, in excess of the antioxidant capacity leads to oxidative stress. [7]

In our study, no retinopathy was found in $23.80 \%$, Grade 1 retinopathy in 23.80\%, Grade 2 in $52.38 \%$ in mild preeclampsia. Grade 3 and 4 retinopathies were not found in this group. Patients of severe preeclampsia had Grade 2 retinopathy in 50\%, Grade 3 retinopathy in $33.33 \%$ and grade 4 in $16.66 \%$. No choroidopathy was found in this study. Retinopathy was found in $84.84 \%$. Reddy et al reported found retinopathy in $59 \%$ of patients comprising of Grade 1 and 2.[8] In our study, Grade 1 and 2 comprised 66.66 $\%$, which correlates with the findings of Reddy et al. Tadin reported retinopathy in 45\%,[9] Ranjan in 40\%, [10] Rasdi in $21.5 \%,[11]$ Karki in $13.7 \%{ }^{[12]}$ Higher percentage of retinopathy in our study could be because of late presentation to the hospital and poor access to antenatal care in remote tribal areas in this economically low resource district. Different racial and population groups studied by other authors may also play a role in the variable percentages of retinopathy.

Retinopathy showed a strong positive correlation $(\mathrm{p}<0.001)$ with systolic and diastolic blood pressure which correlated with the findings of several studies [8,13]

Serum levels of total thiols and hs-CRP were assessed to find correlation with preeclampsia retinopathy.

The mean serum total thiol levels in normal pregnancy control group was $546.0+13.69 \mu \mathrm{M}$ and reduced total thiols levels were noted in preeclampsia which was $427.41+11.00$ $\mu \mathrm{M}$ and in severe preeclampsia which was $361.41+59.9 \mu \mathrm{M}$ ( $\mathrm{p}<0.01)$. Korkmaz et al showed findings similar to ours, with mean thiol levels of $376.1+31.9 \mu \mathrm{M}$ in normal pregnancy, $261.8+49.4 \mu \mathrm{M}$ in mild preeclampsia and $248.3+57.4 \mu \mathrm{M}$ in severe preeclampsia( $\mathrm{p}<0.001)^{[14]}$ Ozler, Yuvachi and de Lucca similarly observed statistically significant lower thiol values in preeclampsia than the normal pregnancy control group. $[15,16,17]$ 
Oxidative stress with decreased levels of thiols occurs in systemic diseases like ischaemic heart disease, pulmonary diseases, chronic kidney disease, alcoholism and Alzheimer's disease. [18,19,20,21,22]

In addition, decreased thiol levels have been found in ophthalmic diseases like keratoconus, pseudoexfoliation syndrome, central serous chorioretinopathy and cataract. [23,24,25,26]

Thorough literature search did not yield any research articles on preeclampsia retinopathy with serum thiols. In our study, a statistically very significant $(\mathrm{p}<0.01)$ negative correlation between retinopathy and serum total thiol in preeclampsia was found.

Serum hs-CRP in our study was $2.63+0.38 \mathrm{mg} / \mathrm{l}$ in normal pregnancy, $8.59+1.15 \mathrm{mg} / \mathrm{l}$ in mild preeclampsia and $13.04+0.26 \mathrm{mg} / \mathrm{l}$ in severe preeclampsia. The hs-CRP showed a very strong positive correlation with retinopathy $(\mathrm{p}<0.01)$. Ayatollahi et al reported values of $9.2+7.1 \mathrm{mg} / \mathrm{l}$ in mild preeclampsia and $12.8+7.3 \mathrm{mg} / \mathrm{l}$ in severe preeclampsia, which were similar to values in our study. [27] Similar observations of increased hs-CRP in preeclampsia were made by other authors. $[28,29,30,31]$ However none of these studies on preeclampsia correlated hs-CRP with retinopathy.

High hs-CRP levels were found in ocular diseases like idiopathic polypoidal choroidopathy and diabetic retinopathy in a large population study. [32] Coban et al and Yanchuan et al measured hs-CRP in hypertensive retinopathy in essential hypertension and found that hs-CRP levels correlated with degree of hypertension and end organ damage including retinopathy. [33, 34] Since retinopathy of preeclampsia is a form of hypertensive retinopathy, occurring in pregnancy, these correlations lend support to the positive correlation between hs-CRP and retinopathy noted in our study.

\section{CONCLUSIONS}

A strong negative correlation $(\mathrm{p}<0.01)$ between total thiols and hs-CRP in retinopathy of preeclampsia was found in our study, but literature search did not yield supporting research data. However, studies done in acute appendicitis and cardiac syndrome $\mathrm{X}$ have found a strong negative correlation to exist between thiol parameters and hsCRP. $[35,36]$

This reinforces the effect of inflammation and oxidative stress, manifested as high hs-CRP and low thiol values, in the pathogenesis of retinopathy of preeclampsia, as several studies support that retinal vascular calibre and endothelial function to be related to oxidative stress and inflammation. [37,38,39]

Supplementation of antioxidants by diet or medicine, to reduce the oxidative burden, in this condition can be a therapeutic option. This, in addition to the available treatment modalities, can prevent and treat retinopathy to avoid permanent sight threatening sequelae.

A larger multicentre sample size, measurement of other oxidative stress parameters and evaluating the role of antioxidants will further help establish the above-mentioned parameters as potential biomarkers of prediction and diagnosis of the severity of retinopathy in preeclampsia.

\section{REFERENCES}

[1] Mihu D, Razvan C, Malutan A, et al. Evaluation of maternal systemic inflammatory response in preeclampsia. Taiwanese Journal of Obsterics and Gynaecology 2015;54(2):160-6.

[2] Uzan J, Carbonnel M, Piconne 0, et al. Pre-eclampsia: pathophysiology, diagnosis and management. Vasc Health Risk Manag 2011;7:467-74.

[3] Bernardi F, Guolo F, Bortolin T, et al. Oxidative stress and inflammatory markers in normal pregnancy and preeclampsia. J Obstet \& Gynaecol Res 2008;34(6):948-51.

[4] $\mathrm{Hu}$ ML. Measurement of protein thiol groups and glutathione in plasma. Methods Enzymol 1994;233:380-5.

[5] Hubel CA. Oxidative stress in the pathogenesis of preeclampsia. Proc Soc Exp Biol Med 1999;222(3):222-35.

[6] Siddiqui IA, Jaleel A, Tamimi W, et al. Role of oxidative stress in the pathogenesis of preeclampsia. Arch Gynecol Obstet 2010;282(5):469-74.

[7] Rajimakers MT, Zusterzeal PL, Steegers EA, et al. Plasma thiol status in preeclampsia. Obstet Gynecol 2000;95(2):180-4.

[8] Reddy SC, Naliah S, Rani S, et al. Fundus changes in pregnancy induced hypertension. International Journal of Ophthalmology 2012;5(6):694-7.

[9] Tadin I, Bojic L, Mimica M, et al. Hypertensive retinopathy and preeclampsia. Collegium Antropologicum 2001;Suppl 25:77-81.

[10] Ranjan R, Sinha S, Seth S. Fundus changes and fetal outcomes in pregnancy induced hypertension: an observational study. International Journal of Scientific Study 2014;2(7):6-9.

[11] Rasdi AR, Nik-Ahmad-Zuky NL, Bakiah S, et al. Hypertensive retinopathy and visual outcome in hypertensive disorders of pregnancy. Med J Malaysia 2011;66(1):42-7.

[12] Karki P, Malla P, Das H, et al. Association between pregnancy-induced hypertensive fundus changes and fetal outcomes. Nepal J Ophthalmol 2010;2(1):26-30.

[13] Bharathi RN, Raju NRS, Prasad PK, et al. Fundus changes in pregnancy induced hypertension: a clinical study. J of Evolution of Med and Dent Sci 2015;4(9):1552-62.

[14] Korkmaz V, Korduglu Z, Asilik M, et al. Impairment of thiol-disulphide homeostasis in preeclampsia. J Matern Fetal Neonatal Med 2016;29(23):3848-53.

[15] Ozler S, Erel O, Oztas E, et al. Serum Thiol/disulphide homeostasis in preeclampsia. Hypertens Pregnancy 2015;34(4):474-85.

[16] Yuvaci HU, Akdemir N, Bostanci MS, et al. Evaluation of the level of Thiol-disulphide homeostasis in patients with mild and severe preeclampsia. Pregnancy Hypertens 2016;6(4):394-9.

[17] De Lucca L, Rodrigues F, Jantsch LB, et al. Deltaaminolevulinate dehydratase activity and oxidative stress markers in preeclampsia. Biomedicine and Pharmacology 2016;84:224-9. 
[18] Kundi H, Ates I, Kiziltunc E. A novel oxidative stress marker in acute myocardial infarction: thiol/disulphide homeostasis. Am J Emerg Med 2015;33(11):1567-71.

[19] Babaoglu E, Kilic H, Hezer $\mathrm{H}$, et al. Comparison of thiol/disulphide homeostasis parameters in patients of COPD, asthma and ACOs. Eur Rev Med Pharmacol Sci 2016;20(8):1537-43.

[20] Qian J, Fang J, Zhu Q, et al. Serum protein thiol levels in patients with hospital-acquired acute kidney injury. Kidney Blood Press Res 2015;40(6):623-9.

[21] Prakash M, Shetty JK, Tripathy S, et al. Serum total thiol status in alcohol abusers. Asian Journal of Biochemistry 2008;3(1):48-51.

[22] Gumusyala S, Vural G, Bektas H, et al. A novel oxidative stress marker in patients with Alzeimers disease: dynamic thiol/disulphide homeostasis. Acta Neuropsychiatr 2016;28(6):315-20.

[23] Gulpumuk B, Koc M, Karatepe MS, et al. Novel assessment of oxidative stress biomarkers in patients with keratoconus: thiol/disulphide homeostasis. Current Eye Research 2017;42(9):1215-9.

[24] Tetkoglu M, Aktas S, Sagdik HM, et al. Thiol/disulphide homeostasis in Pseudoexfoliation syndrome. Current Eye Research 2017;42(6):876-9.

[25] Torkuglu EB, Dikci S, Celic E, et al. Thiol/disulphide homeostasis in patients with central serous chorioretinopathy. Curr Eye Res 2016;41(11):148991.

[26] Elbay A, Ozer OF, Altinisik M, et al. A novel tool reflecting the role of oxidative stress in cataracts: thiol/disulphide homeostasis. Scandinavian J Clin Lab Invest 2017;77(3)223-7.

[27] Ayatollahi H, Hasanzade M, Farzadnia M, et al. Serum level of highly sensitive $\mathrm{C}$ - reactive protein in normal and pre-eclamptic pregnancies. Iran J Pathology 2007;2(3):100-4.

[28] Kumru S, Golakmerdan A, Kutlu S, et al. Correlation of maternal serum high-sensitive C-reactive protein levels with biochemical and clinical parameters in preeclampsia. Eur J Obstet \& Gynecol Reprod Biol 2006;124(2):164-7.
[29] Paternoster DM, Fantinato S, Stella A, et al. C-reactive protein in hypertensive disorders in pregnancy. Clinical and Applied Thrombosis/ Hemostasis 2006;12(3):330-7.

[30] Daniella OM, Costin N, Maria PD, et al. Evaluation of inflammatory markers in pregnant women at risk, for the prediction of preeclampsia. Acta Medica Marisiensis 2014;60(3):94-8.

[31] Hwang HS, Kwon JY, Kim MA, et al. Maternal serum highly sensitive $\mathrm{C}$ - reactive protein in normal pregnancy and pre-eclampsia. Int J Gynaecol \& Obstet 2007;98(2):105-9.

[32] Jonas JB, Wei WB, Xu L, et al. Systemic inflammation and eye diseases. The Beijing Eye Study. PLoS One 2018;13(10):e0204263.

[33] Coban E, Nizam I, Topal C, et al. The association of lowgrade systemic inflammation with hypertensive retinopathy. Clin Exp Hypertens 2010;32(8):528-31.

[34] Yanchuan D, Jian W, Pengquang Z, et al. The relation of serum HS-CRP to risk factors and target organ damage in hypertensive patients. Heart 2012;98(Suppl 2):E1E319.

[35] Elmas B, Yildiz T, Yazar H, et al. New oxidative stress markers useful in the diagnosis of acute appendicitis in children: Thiol/disulphide homeostasis and the asymmetric dimethylarginine level. Pediatr Emerg Care 2017.

[36] Altiparmak IH, Erkus ME, Sezen H, et al. Evaluation of thiol levels, thiol/disulphide homeostasis and their relation with inflammation in cardiac syndrome $\mathrm{X}$. Coron Artery Dis 2016;27(4):295-301.

[37] De Jong FJ, Ikram MK, Witterman JC, et al. Retinal vessel diameters and the role of inflammation in cerebrovascular disease. Ann Neurol 2007;61(5):4915.

[38] Klein R, Klein BEK, Knudtson MD, et al. Are inflammatory factors related to retinal vessel caliber? The Beaver Dam Eye Study. Arch Ophthalmol 2006;124(1):87-94.

[39] Sanchez-Aranguren LC, Pada CE, Riano-Medina CE, et al. Endothelial dysfunction and preeclampsia: role of oxidative stress. Front Physiol 2014;5:372. 